\title{
Study of Reserve and Dynamic Allocation in Emergency Rescue Forces on County Scale
}

\author{
Wen Tian ${ }^{1,2,3}$, Chongfu Huang ${ }^{1,2,3, *}$, Yiran Yin ${ }^{1,2,3}$ \\ ${ }^{1}$ Key Laboratory of Environmental Change and Natural Disaster, Ministry of Education, Beijing Normal University, Beijing 100875, China \\ ${ }^{2}$ State Key Laboratory of Earth Surface Processes and Resources Ecology (Beijing Normal University), Beijing 100875, China \\ ${ }^{3}$ Academy of Disaster Reduction and Emergency Management, Faculty of Geographical Science, Beijing Normal University, Beijing \\ 100875, China \\ 15670994902@163.com
}

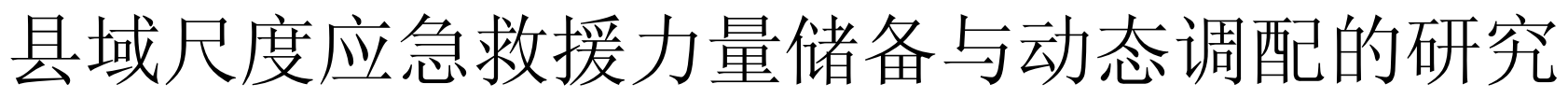

\author{
田雯 $1,2,3$, 黄崇福 $1,2,3, *$, 尹怡然 $1,2,3$ \\ ${ }^{1}$ 北京师范大学, 环境演变与自然灾害教育部重点实验室, 北京100875, 中国 \\ ${ }^{2}$ 北京师范大学, 地表过程与资源生态国家重点实验室, 北京 100875, 中国 \\ 3 北京师范大学, 地理科学学部, 减灾与应急管理研究院, 北京 100875 , 中国 \\ 15670994902@163.com
}

\begin{abstract}
The emergency rescue forces are important for rapid response and emergency treatment to a disaster area. Reserving and allocating the forces directly affect the rescue effect. This paper reviews the data obtained from the "7.11" catastrophic flood emergency rescue in Santai County, Sichuan Province in 2018, and uses the field research to obtain data on the county-level emergency rescue force reserve and dynamic allocation. The study found that: (1) The emergency rescue force reserves of Santai County are mainly composed of armed police, public security, firefighters, flood prevention and rescue teams of townships, enterprises and institutions, as well as some social rescue forces; (2)The emergency rescue forces of the level of village urgently needs to be strengthened in terms of command experience, medical resources, rescue equipment, rescue technology, rescue training, etc. (3)The degree of economic development is the decisive factor among the factors affecting the reserve of emergency rescue forces, and the organization and management efforts, the degree of response of the public, the quality of rescue forces, and the distribution of rescue forces are important factors. (4)The disaster information platform for emergency rescue deployment in the disaster relief process has not been established, and the internet of intelligences is a technology that can be used to realize the dynamic deployment of emergency rescue forces.
\end{abstract}

Keyword s- emergency rescue force, reserve, allocation, Santai County, "7·11" flood

摘要一应急救援力量是灾后快速响应与应急处置的前提, 其 储备与调配直接影响救援效果。本文通过对四川省三台县 2018 年 “7・11”特大洪灾应急救援的回顾, 用实地调研走访获 取的数据, 研究县域尺度应急救援力量储备与动态调配问 题。研究发现:（1）县域内防汛专项应急救援力量储备主要 由武警、公安、消防人员，各乡镇、机关、企事业单位的防 汛抢险队伍, 以及部分社会救援力量等构成; （2）村一级应 急救援力量亟需在指挥经验、医疗资源、救援设备、救援技 术、救援培训等方面加强建设; (3) 应急救援力量储备的影 响因素中经济发展程度是决定因素, 而组织管理力度、民众 响应程度、救援力量素质、救援力量分布是重要影响因素;

*通讯作者：黄崇福，教授, Email: hcongfu@bnu.edu.cn
（4）县域内尚未建立用于救灾过程中应急救援调配的灾害信 息平台, 而智联网是实现应急救援力量动态调配可依托的技 术。

关键词一应急救援力量; 储备; 调配; 三台县; “7·11”洪水

\section{I. 引言}

随着社会经济的快速发展，各类灾害事件时有发 生, 不仅造成了巨大的人员伤亡和经济损失, 而且严重 影响着人们正常的生产、生活, 且随着全球气候变化引 起的极端天气频发, 人类社会将面临更严峻的灾害形 势。以自然灾害为例, 2018 年, 全国各种自然灾害共造 成全国 1.3 亿人次受灾，589人死亡，46人失踪， 524.5 万人次紧急转移安置[1]。因此, 灾后如何快速、有效的 实施应急救援是关键。

应急救援力量是应急救援管理和指挥的基础, 合理 的储备和调配应急救援力量能够实现灾民与救援力量的 精准匹配、提高救援的时效性。现有研究中，应急救援 力量有广义和狭义之分[2], 广义上来说, 应急救援力量 被认为是各种应急救援的能量资源, 其组成包括人力资 源、物力资源等; 狭义上来说，应急救援力量被认为是 参与应急处置的救援队伍的统称。本文采用狭义上的应 急救援力量定义。

现有救援力量储备研究通过不同灾害场景的救灾力 量需求预测来确定救灾力量储备 [3-4]; 或通过与相关标 准匹配评价现有救灾力量储备[5]。其中，对于应急救援 力量储备标准来说, 从横向上看, 西方发达国家自上世 纪 90 年代便建立了应急救援力量管理体制, 相关标准 较为完善, 其构成以消防力量为主, 逐渐呈现构成多元 化、职能多样化的特点, 而我国应急救援队伍建设起步 较晚, 应急救援队伍储备标准尚不完善; 从纵向上看, 一直以来, 我国政府都高度重视应急救援力量的储备工 作，在《中华人民共和国突发事件应对法》、《国家突 发公共事件总体应急预案》、《应急救援队伍建设制 
度》等法律制度中均有相关规定, 近些年来, 随着应急 管理部的成立，应急救援队伍的管理逐渐体系化、制度 化，其构成也逐渐多元化，各级政府的应急救援力量储 备标准也逐渐建立起来。除与标准要求匹配外, 应急救 援力量储备是否符合典型灾害中的应急救援需求最为关 键。

对于应急救援力量救援能力评价来说，贺山峰等人 通过构建指标体系采用层次分析法对河南省各城市气象 灾害应急能力进行评价[6]; 郭晶通过影响因素分析确定 潜变量和观测变量，最终建立用于机场应急救援资源能 力评价的结构方程模型[7]; 戚宏亮等通过云模型处理评 价应急管理能力和应急救援效果 [8]; 曹毅通过建立指标 体系、构建综合评价的数学模型展开评价[9]; 等等。通 过文献梳理发现, 目前, 应急救援力量能力评价中指标 综合评价方法最为成熟。

对于应急救援力量调配来说, 国外学者从运筹学视 角展开研究, 利用仿真技术通过最优化方案支持灾后救 援力量配置决策[10]; 或通过混合算法研究最优应急救 援力量调配路径[11]; 或通过研究智能化调度平台实施 应急救援力量动态调配[12]。国内学者从基于多目标优 化的蚁群算法对救援力量调配路径展开探索[13]; 或基 于地理信息系统研究救援力量调度模型, 优化救援力量 配置[14]; 或基于互联网搭建智能救灾平台, 通过智能 体的参与优化救灾决策方案, 实时动态展现灾情支持救 灾力量精准配置[15]。通过文献梳理发现, 智能化调度 决策支持平台逐渐成为国内外相关领域研究的重点。

在灾害研究过程中, 不同空间尺度具有不同研究效 果, 尺度越小越有利于提高研究结果的精细化程度, 更 有利于针对性的研究区域内应急救援力量情况、支持精 准救援。因此, 本文以县乡为基础的县域尺度应急救援 力量作为研究对象，选取了四川省三台县 2018 年“7·11” 洪水事件为研究实例, 通过实地调研获取与灾害事件对 应的四川省三台县防汗抢险应急救援力量相关数据, 研 究现有应急救援力量储备与调配现状及存在的问题, 并 对研究区建立智能化应急救援力量动态调配平台可能性 进行一定的思考。

\section{II. 研究区概况}

三台县位于四川盆地中部偏北, 绵阳市东南部, 北

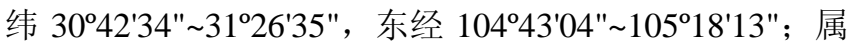
于亚热带季风气候区, 年平均降水量为 876.2 毫米, 降 水在年内和年际变化大，其中 $6 \sim 9$ 月降水量占全年降 水量的 $72.4 \%$; 属川中丘陵地区, 地势北高南低, 海拔 高度 307 米至 672 米; 县境内大小江河溪流 46 条, 均 属于长江支流嘉陵江水系, 其中涪江、凯江、梓江、郪 江为四条大江, 涪江由绵阳市涪城区丰谷镇进入三台县 境内, 经永明、芦溪、花园、老马、刘营、里程、争 胜、灵兴、新德、潼川、百顷出境至射洪香山场, 县境 内流程长 70.65 公里, 流域面积 2660.58 平方公里; 县 域幅员面积 2661 平方公里, 辖 62 个乡镇、1 个街道办 事处, 总人口 148 万, 其中农业人口 123 万； 2018 年， 三台县生产总值达 269.81 亿元，经济发展程度较高。

2018 年 7 月 9 日至 11 日涪江流域上游县市区的强降 雨和局地的大暴雨使得涪江、凯江水位大幅地上涨, 两 江的下泄流量均为历史最大峰值。洪水期间, 永明镇永
和古堰进水口附近、花园镇涪城村和殷家壕, 芦溪工业 集中区，刘营镇大围坝、老马场镇、里程镇回龙村附 近、县城北坝街道办柳林坝、潼川镇涪凯两江滨江公园 人口密集区、古井场镇、黎曙场镇等 40 个镇乡受灾最 为严重, 受灾人口达 25.1 万人; 导致三台县境道路、堤 防、水库、渠系、电力、供水、通信、能源等基础设施 毁损严重; 社会经济损失近 18 亿元。

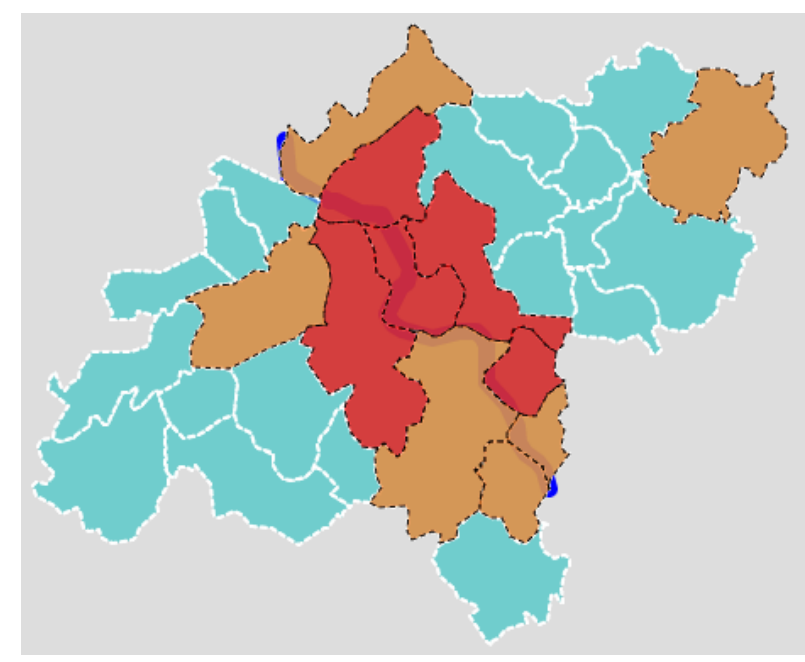

图 1 四川省绵阳市三台县受灾情况图

（注：红色表示受灾最严重区域；棕色表示受灾严重区域；蓝色表示 受灾较轻区域)

\section{III. 三台县应急救援力量储备}

\section{A. 应急救援力量储备现状}

1) 应急救援力量建设

应急救援队伍的组建使得城市在灾害发生时能够提 升快速反应能力, 在有效抢救期内保障居民生命财产安 全, 充分减小灾害事件对居民造成的影响。经过统计, 县内各职能部门的相应队伍建设任务, 见表 1 。其中, 县人民政府负责全面的队伍建设组织工作。

\section{2) 应急救援力量构成}

本次调研时间为 2019 年 6 月 25 日，正值县一级应 急管理局成立初期, 其对应的乡镇级应急管理部门尚未 形成, 资料收集难度较大。因此, 本次共收集 25 个乡 镇应急救援力量数据。根据调研资料可知, 此次 “ $7 \cdot 11$ ” 洪灾为百年一遇的特大洪灾, 以灾前的 2018 年 5 月版 防汛应急专项预案相关规定为例, 县域内应急救援力量 的组成包括武警、公安、消防人员, 各乡镇、机关、企 事业单位的防汛抢险队伍, 以及部分社会救援力量等。 总体来看, 三台县县区、乡镇的防汛抢险应急救援队伍 主要由表 2 中所示的几个部分构成。

目前, 三台县乡镇级常备防汗应急救援队伍总人数 为 2880 人, 本次调研所获取 25 个乡镇常备应急救援队 伍总人数为 1507 人, 具体应急队伍情况见表 3 。除表中 所示的常备应急救援力量外, 乡镇内另有党员干部、民 警、领导干部应急队伍、志愿者服务队、民兵应急分队 等非常备应急救援力量, 其中, 各村按照要求组建 2030 人的民兵应急分队。 
表 1 三台县各职能部门防汛队伍建设任务

\begin{tabular}{|c|c|}
\hline 部门 & 任务 \\
\hline 县人民政府 & 落实防汛抢险队伍的组织工作, 组建防汛抢险队伍。 \\
\hline 县武装部 & 有针对性地加强民兵预备役部队的防汛抢险技能演练, 提高队伍快速反应能力和实战能力 \\
\hline 县防汗指挥部 & $\begin{array}{l}\text { 同武装部建立健全防汗抢险队伍布防方案、调动路线、运送方式和调度制度, 确保抢险队伍在调令规 } \\
\text { 定时间内抵达指定地点。 }\end{array}$ \\
\hline 防汛抢险队伍 & $\begin{array}{l}\text { 编组名册, 确定责任人、责任地段, 召集方式和联系手段, 报县防汛指挥部和武装部备案。由县防汛 } \\
\text { 指挥部统一指挥调度。紧急情况下由绵阳市防汛指挥部统一调度。 }\end{array}$ \\
\hline $\begin{array}{l}\text { 鲁班水库防汛抢险 } \\
\text { 队伍 }\end{array}$ & 由三台县人民政府及防汛指挥部、县武装部指挥调度 \\
\hline $\begin{array}{l}\text { 中型水库防汛抢险 } \\
\text { 队伍 }\end{array}$ & 由水库管理单位指挥调度, 重大险情发生时由市、县防汛指挥部统一指挥调度。 \\
\hline $\begin{array}{l}\text { 小型水库防汛抢险 } \\
\text { 队伍 }\end{array}$ & 由所在乡镇人民政府、武装部组织指挥调度。 \\
\hline 乡镇防汛抢险队伍 & $\begin{array}{l}\text { 以民兵预备役为主, 由乡镇武装部长带队, 以村为单位组织; 机关、企事业单位防汛抢险队伍以干 } \\
\text { 部、职工为主, 由单位主要领导带队, 以部门为单位组织。 }\end{array}$ \\
\hline
\end{tabular}

表 2 三台县应急救援力量构成

\begin{tabular}{cl}
\hline 级别 & \multicolumn{1}{c}{ 构成部分 } \\
\hline 县区 & $\begin{array}{l}\text { 各大公司常备应急救援力量、各事业单位常备应急救援力量、 } \\
\text { 消防大队、武警、公安、部队、医疗救援大队、社会组织力量 }\end{array}$ \\
\hline 乡镇 & 民兵应急分队、镇政府干部、村社干部、党员干部 \\
\hline
\end{tabular}

表 3 三台县应急救援力量情况

\begin{tabular}{|c|c|c|c|}
\hline 类别 & 单位名称 & 救援任务 & 人数 \\
\hline \multirow{2}{*}{ 县一级应急救援力量 } & 公司 & 由政府部门调配 & 344 \\
\hline & 应急管理局 & 抢险工作 & - \\
\hline \multirow{25}{*}{ 乡镇级应急救援力量 } & 光辉镇 & 防汛抗旱 & 270 \\
\hline & 古井镇 & 消防, 防汛救援 & 50 \\
\hline & 曙光乡 & 应急抢险 & 20 \\
\hline & 观桥镇 & 防火、防汛 & 188 \\
\hline & 金鼓镇 & 应急救援 & 30 \\
\hline & 菊河镇 & 应急救援 & 128 \\
\hline & 乐安镇 & 辖区范围内 & 31 \\
\hline & 乐加乡 & 应急抢险 & 30 \\
\hline & 刘营镇 & 防汛 & 35 \\
\hline & 柳池镇 & 抗洪救灾 & 15 \\
\hline & 芦溪镇 & 应急抢险、救援 & 66 \\
\hline & 前锋镇 & 应急抢险 & 35 \\
\hline & 三元镇 & 消防救援 & 12 \\
\hline & 上新乡 & 消防救援 & 12 \\
\hline & 石安镇 & 应急抢险 & 84 \\
\hline & 双乐乡 & 消防、应急抢险 & 52 \\
\hline & 塔山镇 & 应急抢险 & 30 \\
\hline & 潼川镇 & 防汛、灭火 & 135 \\
\hline & 万安镇 & 消防救援 & 30 \\
\hline & 新鲁镇 & 应急抢险 & 44 \\
\hline & 永新镇 & 消防, 防汛 & 30 \\
\hline & 玉林镇 & 防汗抗旱 & 35 \\
\hline & 中新镇 & 应急抢险 & 52 \\
\hline & 忠孝乡 & 应急抢险 & 30 \\
\hline & 黎曙镇 & 灭火、防汛 & 30 \\
\hline
\end{tabular}

\section{3）应急救援力量管理}

以三台县防汛抢险救援力量为例, 当防洪工程发生 重大险情或遭遇特大洪水时, 由县防汛指挥部指挥长决 定请求当地武警、消防人员支援。紧急情况下, 调动武 警、消防、部队参与抗洪抢险时, 必须实行防汛指挥长 高度集中调动制度, 由县防汛指挥长会同武警共同下达 调动命令。县防汗指挥部制定具体方案, 明确武警、消 防、部队参与抢险的人数和布防地段、运动路线, 报县 防汛指挥部后, 由县防汛指挥长统一指挥调度。具体的 应急救援力量管理体系如下图 2 所示:

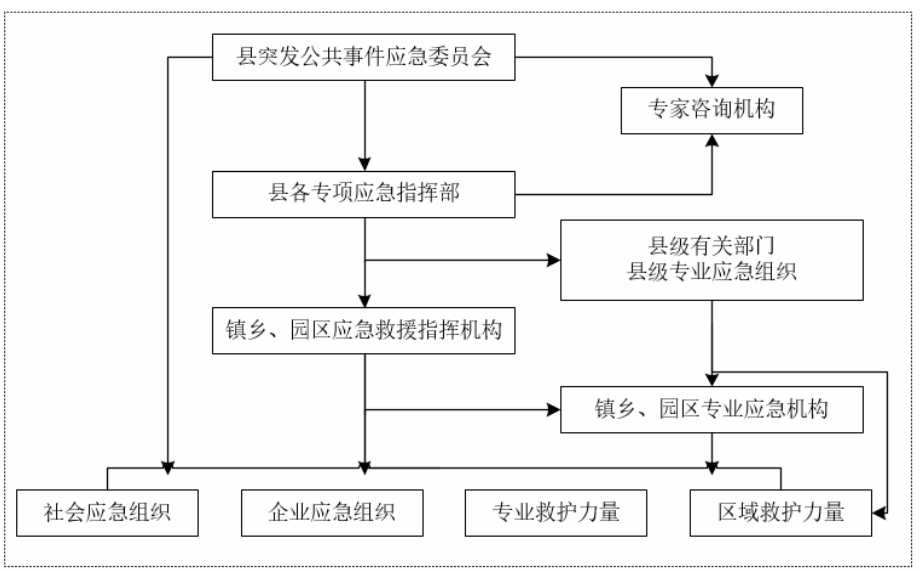

图 2 应急救援力量管理体系

\section{4) 应急救援力量能力评价}

本文尝试展开小规模应急救援力量能力评价的探 索。以三台县分布最为广泛的民兵应急分队为例展开应 急救援力量能力评价。民兵应急分队为强制性建立的村 级应急救援力量, 人员组成为村内干部、党员、青壮年 群众等, 数量在 20-30 人。本文以实地调研对象: 鸡头 垭村民兵应急分队为例, 采用模糊综合评价方法展开评 价: 


\section{a) 指标体系}

选取目前应急救援力量能力评价广泛使用的 5 项指 标作为一级指标, 结合村一级应急救援力量的特殊情况 选取二级指标，指标构成如下表所示:

表 4 应急救援力量能力评价指标

\begin{tabular}{cl}
\hline 一级指标 & \multicolumn{1}{c}{ 二级指标 } \\
\hline 指挥系统 & 经验、体力、知识技能、任务管理、通讯条件 \\
救援队组织结构 & 搜索、救援、技术、保障、医疗 \\
救援队行动能力 & 搜救能力、医疗能力、物资设备 \\
救援队支持能力 & 人力、物力、技术 \\
救援队保障能力 & 装备、培训、保险 \\
\hline
\end{tabular}

b) 权重确定

本文采用模糊综合评价法确定权重, 该方法能够通 过两两比较将人们的思维过程和主观判断数学化, 一定 程度上减少计算结果的主观性。

\section{c) 评价矩阵}

通过建立评价等级及对应分数, 征询相关领域专家 学者以及与村内干部群众访谈两种途径进行打分, 得到 救援力量的评价矩阵; 在得到评价矩阵后, 通过权重代 入分别计算评价结果; 通过将一级指标评价结果作为评 价目标层模糊判断矩阵, 根据模糊变换得到各指标评价 结果。

\section{d) 评价结果}

在此不罗列数据, 仅阐述评价结果。根据评价结果 显示: 在指挥系统方面, 任务管理评分最高, 原因在于 指挥者多为村支书, 其在村内的各方面素质较突出, 然 而, 由于鸡头垭村支书在村内生活时间较短, 因此与实 际情况相结合的指挥经验不足, 指挥经验得分较低; 在 救援队组织结构方面, 医疗评分不高, 由于村级卫生资 源宜乏, 需加强医疗方面资源的储备和供给; 在救援队 行动能力方面, 物资设备得分最低, 而在此次调研中了 解到此次洪灾影响范围很大, 但是用于搜救的冲锋舟设 备数量少, 不足以支持救援; 在救援队支持能力方面, 技术得分最低, 由于救援人员的受教育水平参差不齐, 因而搜救技术仅靠经验支持; 在救援队保障能力方面, 培训得分最低, 由于县域范围内仅展开对于镇一级救援 力量的培训, 但村一级应急救援力量的相关培训欠缺。

\section{B. 应急救援力量储备影响因素分析与对策建议}

\section{1) 经济发展程度}

此次“7·11”洪水灾害事件中应急救援力量不仅包括政 府层面力量, 而且包括灾区民众的自救互救力量, 而后 者为主要力量。在调研期间, 通过与乡镇村民们进行访 谈得知，政府部门并没有及时赔付村民们的灾害损失， 而在此情况下，百年一遇的“7·11”特大洪灾并未影响村 民们的正常生产、生活。

可见区域的经济发展水平是影响应急救援力量储备 的首要因素。经济发展程度较高, 则区域应急救援力量 的需求也就越大, 相应的应急救援力量储备能力越强, 储备人员数量也就越多, 应急保障能力也就越强。在此 提及抗逆力这一概念, 即个人或社区找到内在优势和资 源以有效应对长期压力的能力[10], 抗逆力主要与经济 发展程度相关。因此, 通过大力发展经济, 如其具有特
色的麦冬产业、沱鸟养殖产业等, 提高民众的收入水平 能够有效提升灾区民众的灾害抗逆力。

\section{2) 组织管理力度}

根据调研资料显示, 此前三台县的应急救援力量主 要由政府民政部门统一组织管理, 由于尚未形成成熟的 管理办法, 加之重视程度不高而疏于管理, 导致灾后救 援的反应速度和反应效率不高。此外, 在与应急管理局 相关人员访谈时得知, 目前县内应急救援力量的组建大 主要是采用 “上传下达”模式, 其应急救援力量管理与市 一级的相关政策与规定直接相关, 导致应急救援力量组 建的自主性较差。因此, 通过参考应急救援力量分级储 备标准, 加强应急救援队伍储备的管理力度, 提高应急 救援力量科学化管理水平, 增强县域级别应急救援力量 组建的自主性, 是增强救援效果行之有效的方法。

\section{3) 民众响应程度}

经过调研发现, 三台县乡镇级民众参与防灾减灾工 作的热情较高, 但由于青壮年外出务工情况较多, 因而 常备应急救援人员数量仍是不足, 需继续加强政策宣 传, 鼓励回乡创业。此外, 需开展防灾减灾知识的宣传 教育, 引导民众参与到防灾减灾中。民众的支持和参与 是应急救援力量储备的前提和保障。通过民众的参与, 扩大应急救援力量的影响力和辐射范围, 能够在灾害发 生时, 吸引更多的民众参与到救灾中。

\section{4) 救援力量素质}

应急救援力量的素质水平是影响救援效果的重要因 素, 主要表现在应急救援人员的选拔和培训方面。三台 县应急救援力量的核心部分为消防大队, 专业素质较 强, 但是乡镇级的应急救援力量专业素质参差不齐, 救 援技能掌握程度不高。因此, 通过增加乡镇级救援力量 的技能培训、乡镇与乡镇间的学习交流等, 提升其应急 救援能力, 一定程度上改善应急救援效果。

\section{5) 救援力量分布}

救援力量的位置与分布影响应急救援的响应速度。 三台县应急救援力量分为县、乡镇、村三级, 应急救援 力量覆盖范围广, 但是应急救援力量的科学规划与合理 分布值得考虑。对于灾害风险较大的区域, 其应急救援 力量的分布应较多。因此, 通过常见灾种的灾害风险分 析, 确定各个区域的灾害风险等级, 进一步合理规划应 急救援力量的分布十分重要。

\section{IV. 三台县应急救援力量调配}

\section{A. 应急救援力量调配现状}

三台县应急救援力量跨区域调配过程中, 需在县应 急委的统一指挥和协调下, 事发地政府和有关部门（包 括公安、交通、消防、安全、卫生、供水、供电、供 气、市政、疾病防控、防汗、地震、国土资源、气象、 环保、人防等部门) 以及县级有关部门和单位建立对口 支援关系, 按照各自职责应急联动, 共同实施应急处 置。在依靠全县基本应急救援力量难以有效控制或无法 控制事态时, 由县应急委及时商请驻三台部队、武警和 三台县行政区域内省、市有关单位进行应急增援, 必要 时报请市及市级有关部门增援。即应急救援力量调配在 两种情况下进行: 第一, 灾害强度适中, 县级应急救援 力量足以支持救援; 第二, 灾害强度较大, 县级应急救 
援力量难以支持救援。目前, 三台县应急救援力量处于 自给自足状态, 灾害发生后, 在县域范围内进行应急救 援力量调配的现有措施是乡镇级灾情管理者在该区域受 灾后根据受灾情况自救互救, 在自救无法满足需要时向 上级请示, 请求应急救援力量; 当发生特别重大、重大 突发公共事件, 依靠一般应急处置队伍和社会力量无法 控制和消除其严重危害, 事态有扩大、发展趋势时, 将 实施扩大应急行动, 县政府按照有关程序采取有利于控 制事态的非常措施并向上级报告, 请求有关方面支援。 总之，三台县目前的应急救援力量调配仍处于一个“自 下而上”的反馈型模式，存在欠缺时效性等诸多问题。

\section{B. 应急救援力量动态调配的可能性}

随着互联网时代的到来, 网络连接着各种各样的资 源, 而应急救援力量就是其中一种。通过网络实现应急 救援力量动态调配, 能够满足灾区调配需求。首先, 在 技术层面, 现有的地理信息系统技术已经得到长足发 展, 通过 WebGIS 开发, 利用网络地图 API, 能够实现 网上地图的实时呈现, 且目前卫星技术十分发达, 通过 实时定位锁定应急救援队伍地点, 并在网络地图中实现 可视化, 能够展现应急救援的动态过程; 其次, 在算法 层面, 目前最为成熟的是多目标优化算法, 通过设置目 标函数, 得到配置的优化方案, 其求解也有许多成熟的 算法, 如模拟退火算法、蚁群算法、遗传算法等。

现有的已经实现的应急救援力量动态调配平台有中 国应急信息网, 但其实操性不强; 此外, 各大公司分别 搭建应急救援动态平台，如西南油气公司的应急救援平 台。因此, 依托于现有的成熟技术, 实现应急救援力量 动态调配具有较大可能性。结合三台县来说, 三台县目 前的灾害信息平台尚未搭建，相关技术并不完善，因 此, 需尽快建立专家团队展开相关研究。

智联网 (Internet of Intelligences)这一概念由黄崇福教 授在 2011 年提出[16], 现已发展了包括智联网驱动的风 险雷达、海洋环境风险管理智联网平台、风险时效性评 价等在内的 10 个智联网平台[17], 是中国灾害风险分析 领域先进的在线灾情评估平台。目前，正在打造以救灾 为主题的智联网, 其核心目标是实现一个综合性、信息 化、智能化的救灾平台, 通过灾情数据计算给决策者提 供可视化的灾情情况。智联网正是实现应急救援力量动 态调配可依托的技术, 而救灾智联网应急救援力量动态 调配模块可作为其设计的概念模型, 这将在下一步的研 究中继续展开。

\section{V. 结论与讨论}

本文通过实地调研的方式获取与“7·11”洪水灾害事件 对应的四川省三台县防汛抢险应急救援力量相关数据, 通过对调研数据的梳理与分析: (1) 从应急救援力量 建设、应急救援力量构成、应急救援力量管理三个方面 分析应急救援力量储备现状，并以鸡头垭村民兵应急分 队为例, 运用模糊综合评判法对村一级应急救援力量的 能力展开评价, 结果显示村一级应急救援力量亟需在指 挥经验、医疗资源、救援设备、救援技术、救援培训等 方面加强建设; (2) 从经济发展程度、组织管理力
度、民众响应程度、救援力量素质、救援力量分布这 5 个方面分析影响三台县应急救援力量的因素, 发现经济 发展程度是决定性因素; (3) 三台县目前的应急救援 力量调配仍处于一个“自下而上”的反馈型模式, 需尽快 建立专家团队展开相关研究, 且在现有技术支撑下, 实 现应急救援力量动态调配具有较大可能性, 而智联网正 是实现应急救援力量动态调配可依托的技术, 这将在下 一步的研究工作中展开探索。

\section{致谢}

本项目受国家重点研发计划课题 “重大自然灾害多层 级精准救助关键技术研究” (编号: 2017YFC1502902) 和国家自然科学基金项目“独立多灾种年度财产损失综 合风险的信息扩散合成范式研究”（编号：41671502） 联合资助。

\section{参考文献}

[1] 李玉坤. “2018 年全国自然灾害共造成 1.3 亿人次受灾,” N/OL.新 京报, 2018.

https://baijiahao.baidu.com/s?id=1622082923725812197

\&wfr=spider\&for=pc.

[2] 王靖元, 刘立文, 刘晓平, 等, “我国应急救援力量构成及其存在问题 研究,”武警学院学报,vol. 32, issue 12, pp. 31-36, 2016.

[3] 陈浩, 王瑛, 王阳, 等, “基于专家方法的县级救灾物资库存研究: 以 滇西北地震灾害为例,” 北京师范大学学报(自然科学版), vol. 47, issue 2, pp. 202-206, 2011.

[4] 陈文沛, 陈艺娴, “关于我国救灾应急物资的需求预测方法概述,” 商, vol. 2015, issue 47, pp. 55-55, 2015.

[5] 王瑛, 张薇, 黄晓霞,等, “䒨城历史巨震情景的山东省灾情评估研 究——以需转移安置人口为例, ”自然灾害学报, vol. 22, issue 06, pp. 026-32, 2013.

[6] 赵庆风, 贺山峰, “河南省城市气象灾害应急能力评价与提升策略 研究,”防灾科技学院学报, vol. 21, issue 01, pp. 50-59, 2019.

[7] 郭晶. “机场应急救援资源能力及其影响因素研究, ”北京: 首都经 济贸易大学, 2018.

[8] 戚宏亮, 宁云才, “煤矿应急救援能力评估研究, ”煤炭技术, vol. 36, issue 4, pp. 337-340, 2017.

[9] 曹毅, “地震救援队应急救援能力综合评价及应用研究, ”长沙：国 防科技大学, 2008.

[10] Goldberg J. "Operations research models for emergency services vehicles,” EMS Management Journal,the Deployment, vol. 1, issue 1, pp. 20-39, 2004.

[11] Jie C., Han H., Jiang Y. P., et al. "Emergency rescue vehicle dispatch planning using a hybrid algorithm," International Journal of Information Technology \& Decision Making, vol. 17, issue 10, 2018.

[12] Jara-Olmedo A, Medina-Pazmino, Wilson, Tozer, Tim, et al. "Eservices from emergency communication network: aerial platform evaluation," Proceedings of 2018 International Conference on eDemocracy \& eGovernment (Ambato, Ecuador, April 4-6, 2018), pp. 251-256, 2018.

[13] 谈晓勇, 林鹰, “基于改进遗传蚁群算法的灾后救援路径规划, ”计 算机工程与设计, vol. 2014, issue 7, pp. 2526-2530, 2014.

[14] 张乾, 闵浩文, 张黎明,等, “基于空间关系的海上应急救援力量调度 模型,”地球信息科学学报, vol. 20, issue 6, pp. 772-780, 2018.

[15] Huang C. F.. "Principle of internet of intelligences and development of its core technology,” Journal of Risk Analysis and Crisis Response, vol. 7, issue 3, pp. 146-155, 2017.

[16] 黄崇福,“风险分析在线服务的智联网,” Journal of Risk Analysis and Crisis Response, vol. 1, issue 2, pp. 110-117, 2011.

[17] 黄崇福, “智联网原理及其核心技术的发展,” Journal of Risk Analysis and Crisis Response, vol. 7, issue 3,pp. 146-155, 2017 